\title{
Gallstone ileus as a cause of upper intestinal obstruction
}

\author{
Emergency Room of the Hospital das Clinicas, College of Medicine, \\ University of São Paulo (USP), Trauma Surgery Discipline - São Paulo, Brazil
}

\begin{abstract}
Gallstone ileus, a mechanical intestinal obstruction caused by the passage of a gallstone into the intestinal lumen through a fistula, although not common, deserves to more carefully studied due to its morbidity and mortality. Its incidence among older-age groups explains its association with chronic and degenerative diseases, which increase the complexity of the treatment choice. The need and appropriateness of a surgical approach to a cholecystenteric fistula to solve the obstructive emergency, in a one or two stage procedure, has been discussed in the literature. It has also been reported that gallstone ileus is an uncommon cause of upper intestinal obstruction. Intestinal obstruction is seen more frequently after a gallstone impacts at the ileocecal valve. The authors report a case of gallstone ileus as a cause of upper intestinal obstruction and discuss its diagnosis and treatment.
\end{abstract}

UNITERMS:Intestinal obstruction. Gallstone ileus. Cholecystenteric (biliary-enteric) fistula.

\section{INTRODUCTION}

Gallstone ileus is a mechanical obstruction caused by a gallstone, orginating in the gallbladder, which passes through a cholecystienteric fistula and impacts in the intestinal lumen. An increase in gallstone ileus, associated with increasing longevity, has been observed in developed countries over the past several years. Gallstone ileus accounts for 1-4 percent of all intestinal obstructions. ${ }^{1-3}$

Such incidence is statistically significant in patients over 70, predominately women. In $80-90$ percent of the cases in this age group, patients also have associated diseases which affect one or more systems, mainly cardiovascular diseases and diabetes mellitus. ${ }^{1.2 .4-6}$

\section{Adress for correspondence:}

Luis Fernando Correa Zantut

Av, Brig. Luís Antonio, 4521 - Jardim Paulista

São Paulo/SP - Brasil - CEP 01401-002
Mortality rates vary between $12-27$ percent, with deaths being related to critical conditions, and especially to these associated diseases. ${ }^{1.4 .7}$

Most gallstones cause obstruction by impacting the distal ileum. ${ }^{2.67}$ Treatment remains controversial in regards to the true need to reach the cholecystenteric fistula during initial operative procedures. ${ }^{1.4 .8 .9}$

The objectives of this report are to describe an upper intestinal obstruction by gallstone ileus, diagnosed preoperatively by computerized tomography (CT); and to discuss the adequacy of the instituted treatment.

\section{CASE DESCRIPTION}

An 80-year old patient, with mild cardiac failure and a history of two previous strokes that had left minimal sequelae, was admitted to another hospital. She had been vomiting food residues for four days, and had had no prior symptoms of cholecystopathy. 
An upper digestive endoscopy showed gastric and duodenal food stasis and acute gastroduodenitis. In the following days, in addition to a simple roentogenogram of the abdomen, an ulstrasonography and a CT scan were performed. Exams showed air in the bile tree, no stones in the gallbladder, thickened duodenal walls, and a radiopaque image suggesting an impacted stone at Treitz' arch (Fig. 1).

The patient then began to complain of abdominal pain and distention, a worsening of the vomiting, and a stoppage of gas and fecal elimination. After wards, she was transferred to our hospital. Admitted seven days after the onset of the symptoms, she was anicteric, afebrile, and presented signs of intestinal obstruction.

After preoperative preparation, she was submitted to a laparotomy. A cholecystoduodenal fistula and a 3.5 $\mathrm{cm}$ impacted gallstone were found in the distal jejunum. The gallstone fragmented during manipulation, so a manual propulsion of the fragments and the contents of the colon was performed.

As the patient's condition was favorable, cholecystectomy and a transverse suture of the duodenum were carried out at the fistula site. During surgery, a radiographic evaluation of the bile ducts was normal, and the peritoneal cavity was drained. Total time under anesthesia was six hours, and no blood transfusion was necessary. The patient showed a dynamic ileus for five days with no other complications. She was discharged on day 13.

\section{DISCUSSION}

Gallstone ileus clinical findings are variable. Symptoms may begin 4-8 days prior to intestinal obstruction. These initial symptoms may reflect the intermittent migration of the gallstone until final impaction, which usually occurs near the ileocecal valve. ${ }^{1.26,7}$

In the present case, the clinical findings suggest multiple migrations along the small intestine. Such migrations would account for the variable symptoms presented by our patient, and the surgical finding of the stone distally from the site indicated by the preoperative CT scan.

\section{PATHOPHYSIOLOGY}

Biliary-enteric fistulas have many known causes. One of them is a duodenal ulcer perforated into the bile ducts, which should not be mistaken for cholecystenteric fistulas,

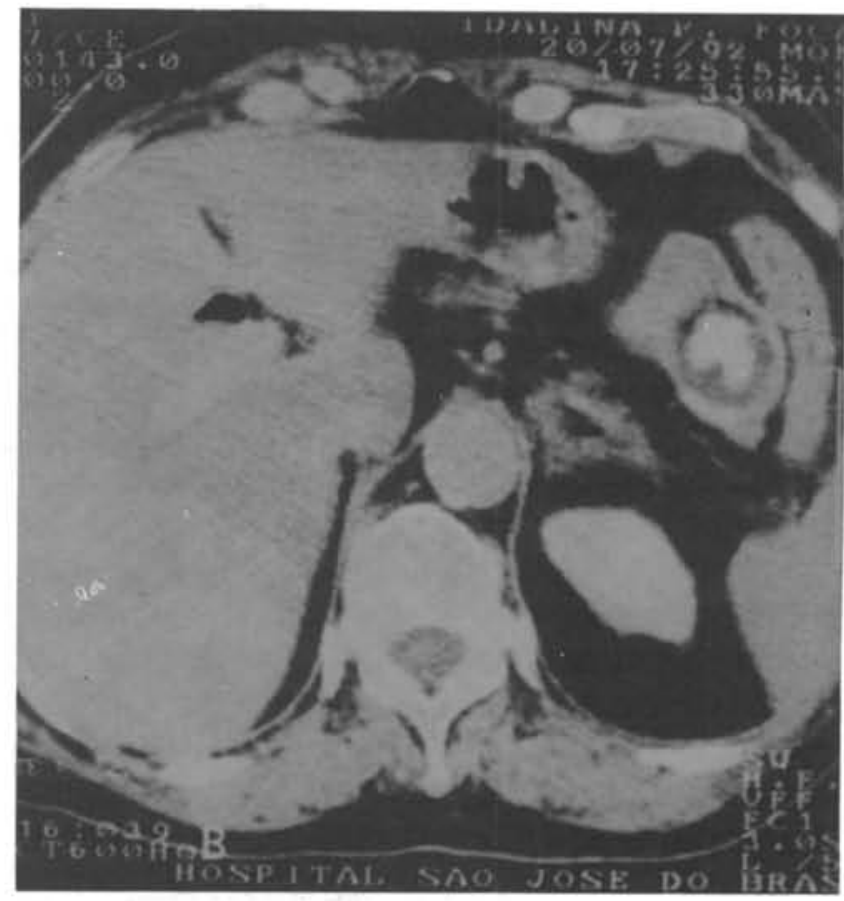

Figure 1 - Abdominal computerized tomography: Air in the bile tree and a $3.5 \mathrm{~cm}$ image with peripheral laminar and crude central calcifications, corresponding to an impacted gallstone at the level of Treitz' arch.

which are consequences of repeated inflammatory episodes in the gallbladder.

These episodes cause pericholecystitis and adherence to neighboring organs. Ulceration due to impaction on the gallbladder wall may, by its contiguity, affect the adhered bowel wall. This would allow the gallstone to pass into the intestinal lumen.

\section{CLINICAL MANIFESTATIONS}

About one-third of patients do not report previous symptoms of bile disease, and only one-third report episodes that could be related to recent acute cholecystitis. ${ }^{2.5 .7 .10} \mathrm{In}$ spite of the difficulties in gathering data on our patient's history, it was possible to conclude that she had not presented any previous symptoms of bile disease prior to this event.

A gallstone that passes through a fistula may be eliminated through vomiting or feces, or may become lodged and obstruct the intestinal lumen. Gallstone ileus frequently causes colicky abdominal pain, bilious or eventually fecal vomiting, and, rarely, jaundice. A differential diagnosis involves other causes of small bowel obstruction and mesenteric ischemia. 
Prompt diagnosis is not always possible, and in some cases, diagnosis is confirmed only during laparotomy. Some authors report surgical procedures carried out 3-5 days after admission, due to diagnostic difficulties or the need to stabilize any associated organic failure. ${ }^{3.4 .10 .11}$

\section{LABORATORY EXAMS}

Clinical findings are confirmed by roentgenograms, ultrasonographies, CT, and upper digestive endoscopy. Simple abdominal roentgenograms of gallstone can be evaluated for Rigler's triad: mechanical obstruction, air in the bile tree, and an usually-located or migrating radiopaque stone. ${ }^{2.12 .13}$ Two of these signs appear in at least half of gallstone ileus patients.

Air in the bile tree is frequently related to previous bile duct laparotomy or to the failure of the Oddi's sphincter. For this to occur, the cystic duct must be pervious or there must a fistula leading into the bile duct.

Another radiographic sign is the observation of two air-fluid levels in the right subcostal region; the medial one is the duodenum and the later one is the gallbladder. The presence of gases over the gallbladder frequently makes this sign difficult to see.

A contrasted roentgenogram may identify the fistula and the level of mechanical obstruction.

Abdominal ultrasonography detects cholecystenteric fistulas, residual cholelithiasis, and impacted gallstones. ${ }^{1.10 .12}$ However, two facts must be remembered: 1. Residual cholelithiasis may not occur, and 2. Its presence may not be detected by ultrasonography.

An abdominal CT may show gallstones not detected in the roentgenogram or ultrasonography. It can identify gas or contrast in the bile ducts or gallbladder, interpreted as signs of biliary-enteric fistula. $^{12}$

Gallstones may be identified and removed during endoscopy. Otherwise, laparotomy is required.'

\section{DIAGNOSIS}

In this case, a syndromic diagnosis was obtained clinically following the development of signs and symptoms clearly indicating obstruction. As the simple radiographic image was unclear, the etiologic diagnosis was confirmed only through CT. Rigler's triad was later identified on the roentgenogram.

\section{SURGICAL TREATMENT}

Gallstone ileus should be preferentially treated by laparotomy. It is also possible to remove some obstructions by endoscopy, and reportedly in a few cases, by shockwave lithotripsy.'

Impacted gallstones are reported to be found mostly in the small intestine, and are not common in the colon. According to several authors, obstructions occur in 50-70 percent of the cases within the distal ileum, including the ileocecal valve, $20-40$ percent in the proximal ileum or jejunum, and the other 10 percent occur in the duodenum. ${ }^{1.14 .15}$

The most common obstruction site in the colon is the sigmoid. This usually occures because of the presence of a cholecystocolonic fistula and a previous sigmoid colon stricture caused by a past diverticulitis crisis. Calculi capable of causing obstruction would have not been able to pass through the ileocecal valve without the presence of a colonic fistula. ${ }^{14.15}$ In most cases, there is only one obstructive gallstone, which varies from $2-5$ $\mathrm{cm}$ in diameter. ${ }^{1.7 .11 .14}$

The most common fistulas are, in decreasing order of frequency: cholecystoduodenal; cholecystocolonic; cholecystoduodenocolonic; and choledochoduodenal. Colonic fistulas occur more frequently in the hepatic flexure, the transverse colon, and uncommonly, in the sigmoid colon. ${ }^{2.16}$

Early recurrence happens when there are multiple gallstones and the fistula has been inadequately treated. Multiple gallstones are usually multifaceted.

Since the migration of two or more gallstones is possible, inspection of all intestinal segments during surgery is recommended. . $^{\text {X.13.16.17 }}$

The literature on gallstone ileus discusses three types of surgical options:

1. Enterolithotomy, following removal of the obstruction.

2. A two stage procedure - the first stage is enterolithotomy, and, 3 or 4 weeks later, cholecystectomy and removal of the cholecystenteric fistula.

3. A one-time laparotomy, including enterolithotomy and cholecystectomy with removal of the fistula.

Criteria which should guide treatment are: age; acid/ base and hydroelectrolytic equilibrium; associated 
diseases; residual cholelithiasis; and the presence of acute inflammation in the cholecystenteric fistula. ${ }^{3.8 .11}$

\section{SURGICAL TECHNIQUES}

Enterolithotomy should be done through a longitudinal incision proximate to the obstruction at the antimesenteris border, followed by a transverse suture. Eventually, an enterectomy will be necessary, particularly if there is an intestinal perforation.

Manual propulsion of the cecus and gallstone tripsy may be performed only in selected cases, as there is a risk of injury to the bowel wall. ${ }^{1.18}$

In the case of multiple gallstones, an incision next to the largest ones permits the extraction of the smaller ones.

In sigmoid colon obstruction, authors describe proximal colotomy for stone removal, just as in extraction by colonoscopy. However, when the sigmoid colon is narrowed, resection is preferred, with the removal of the segment with the stones. ${ }^{14.15}$

In this case, the absence of residual stones was demonstrated by preoperative exams, and thus a two-stage laparotomy could have been considered. However, as clinical conditions permitted, a one-stage procedure was chosen. The satisfactory evolution of the patient confirmed the appropriateness of the this treatment.

It should be noted that, although manual propulsion of stones is not usually recommended, due to the risk of tissue injury and distal obstruction of the sigmoid colon, it was done in this case because of the fragmentation of the stone after manipulation.

\section{POSTOPERATIVE RESULTS}

Spontaneous closing of the cholecsytenteric fistula may occur after gallstone migration, when there are no residual calculi and the cystic duct is pervious. ${ }^{9.19 .20}$ When cholecystectomy and correction of the biliary-enteric fistula are not performed, some complications may result, such as: cholangitis; acute choledochocystitis; recurrent intestinal obstruction; choledocholithiasis; fistural bleeding; and gallbladder carcinoma.

Cholangitis occurs in 10 percent of the cases with cholecystenteric fistula persistence, and in 60 percent of those with cholecsytenteric fistula. Acute choledochocystitis may occur due to residual cholelithiasis, and recurrent gallstones can be observed in 5-10 percent of the cases. Cholelithiasis may also cause cholangitis. Bleeding may occur due to passage of the gallstone through the fistula. The incidence of gallbladder carcinoma in patients with persistence is 15 percent, compared to 0.8 percent in the general population. ${ }^{5.17 .19}, 20$

\section{CONCLUSION}

The definite correction of the bile duct does not increase mortality in relation to other forms of treatment, in spite of the increased anesthesia/surgery time. ${ }^{1.4 .6 .8 .11}$

The one-stage procedure seems to be indicated when local and systemic conditions permit. The two-stage procedure does not raise mortality, but it does mean a longer hospital stay, as it involves two different procedures, usually on a elderly patient.

When bile duct correction is not possible during initial surgery, bile disease or residual cholelithiasis symptoms justify a subsequently programmed reintervention.

Patients who remain asymptomatic and without any visible stones after enterolithotomy may be followed up by a series of ultrasonographies, instead of undergoing another surgery.

In high-risk patients, who after enterolithotomy still have residual colethiasis, shock wave lithotripsy or chemical dissolution of the stones should be considered. However, further studies are needed on the repercussions of these treatments on chronically-inflamed areas, such as those found in cholecystenteric fistulas.' 


\section{RESUMO}

Objetivo: Os autores apresentam caso de fleo biliar como causa de obstrução mecânica alta, discutindo aspectos referentes ao diagnóstico e tratamento. Discussāo e Resultados: A obstruçāo intestinal mecânica causada pela passagem de cálculo da vesicula biliar para a luz intestinal através de fistulizaçāo, apesar de infreqüente, merece estudo pela morbi-mortalidade que apresenta. A incidência em faixas etárias mais avançadas explica a associaçāo com doenças crônico-degenerativas, aumentando a complexidade da decisāo terapêutica. A literatura discute a necessidade e a oportunidade da abordagem cirúrgica da fistula colecisto-entérica em um ou dois tempos diante da resoluçăo da urgência obstrutiva e faz referência do íleo biliar sendo a causa de obstruçāo intestinal alta como excreçāo. A obstrução intestinal verificada com maior frequência ocorre quando da impactaçăo do cálculo biliar a nível da válvula ileo-cecal.

\section{REFERENCES}

1. Clavien PA, Richon J, Burgan S, Rohner A. Gallstone ileus. Br J Surg 1990;77:737-42.

2. Kasahara Y, Umemeura H, Siraha S, Kuyama T, Sakata K, Kubota H. Gallstone ilues. Am J Surg 1980;140:437-40.

3. Raf L, Spagen L. Gallstone ileus. Acta Chir Scad 1971;137:665-75.

4. Day EA, Marks C. Gallstone ileus. Am J Surg 1986;151:572-6.

5. Dietz DM, Standage BA, Pinson CW, McConnell DB, Krippaehne WW. Improving the outcome in gallstone ileus.

6. Van Landingham SB, Broders CW. Gallstone ileus. Surg Clin North Am 1982;62(2):241-7.

7. Fox, PF. Planning the operation for cholecystoenteric fistula with gallstone ileus. Surg Clin North Am 1970:50(1):93-107.

8. Adroni A, Cap[ocasale E, Livrini M. Criteri per una scelta razionale di trattamento dell'ileo biliare. Minera Chir 1991;46:1033-7.

9. Syme RG. Management of gallstone ileus. Can J Surg 1989;32:61-4.

10. Van Hillo M, Van de Vliet JA, Wiggers T, Obertop H, Terpstra OT, Greep JM. Gallstone obstruction of the intestine: An analysis of ten pateints and a review of the literature. Surgery 1987;101(3):273-6.
11. Warshaw AL, Bartlett MK. The choce of operation for gallstone intestinal obstruction. Ann Surg 1966;164(6): 1051-5.

12. Braver JM, Clarke PD. A roentgenologic clinical pathologic case. Invest Radio 1990;25:757-8.

13. Beutow GW, Blaubitz JP, Clampton RS. Recurrent gallstone ileus. Surgey 1963;54(5):716-24.

14. Pryor JH. Gallstone obstuction of the sigmoid colon with particular reference to aetiology. Br J Surg 1959;47:259-61.

15. Serrano R, Montan A, Lacasa J. Coleitiasis y fistula colecistocolonica: Una rara forma de ileo biliar. Rev Esp Enf Digest 1990;77(1):55-7.

16. Piedad $\mathrm{OH}$, Wels PB. Spontaneous internal biliary fistula: obstructive and nonobstructive types.

17. Cooperman AM, Dickson ER, ReMine WH. Changing concepts in the surgical treatment of gallstone ileus. Ann Surg 1968;167(3):377-83.

18. Kapel O. Operative treament of gallstone ilues without enterotomy. Acta Chir Scand 1974;95:54-60.

19. Palomar de Luis M, Tubia Landaberea JI, Elora Orue JL. Fistual biliodigestivas espontaneas. Rev Esp Enf Digest 1990;77(1):33-8.

20. Svartholm E, Anren-Sandberg A, Evander A, Jarhult J, Thulin A. Diagnosis and treatment of gallstone ileus. Acta Chir Scand 1982;128:435-8. 